\title{
Climate variability and human impacts in Central and Eastern Europe during the last two millennia
}

Wojciech Tylmann ${ }^{1}$ and Martin Grosjean ${ }^{2}$

Gdansk, Poland, 17-19 June 2015

Proxy-based comprehensive regional climate reconstructions for the past 2000 years provide critical insight into the fundamentals of natural climate variability and the detection and attribution of anthropogenic climate change in the $20^{\text {th }}$ century. Moreover, it is increasingly recognized that anthropogenic land-use and land-cover changes over the same period of time have played an important role in modifying the regional atmosphere and ecosystem development. Although Europe has better paleoclimate data coverage than many other parts of the world, information from Central and Eastern Europe is still scarce and mostly missing in comprehensive regional climate reconstructions (PAGES 2k Consortium 2013). However, the extraordinarily rich sources of early instrumental and documentary data from historical climatology, recent discoveries of many varved lake sediments in Poland (Tylmann et al. 2013), new developments of quantitative hydroclimatic proxies from peat bogs (Lamentowicz et al. 2011), and new insights into anthropogenic vegetation and land-cover changes have drawn the attention of paleoecologists and paleoclimatologists to Central and Eastern Europe.

Under the umbrella of the three PAGES working groups, Euro-Med2k, the Varves Working Group and LandCover6k, 90 scientists from 14 countries gathered at the University of Gdansk, Poland, to (i) discuss existing and new data sets from Central and Eastern Europe; (ii) explore ways the scientific community from this part of Europe could be better involved in ongoing PAGES activities, and (iii) stimulate research along the agendas of the three PAGES working groups. More precisely, the conference aimed to fill regional data gaps in Central Europe, to improve the quality of paleoclimate data sets (calibration, resolution, chronology, interpretation), to work towards data synthesis and comprehensive multi-site, multi-proxy climate reconstructions, and build our understanding and ability to discriminate between the multiple influences on ecosystems (climate, human, ecosystem evolution, etc.).

Several oral and poster presentations demonstrated the potential of tree-ring research along $\mathrm{W}-\mathrm{E}$ and $\mathrm{N}-\mathrm{S}$ transects across Central and Eastern Europe. Within this area, trees are sensitive both to temperature and humidity, and this sensitivity varies across the seasons. Additionally, the challenges of temperature reconstructions derived from temperate lowland trees were addressed.

Taking advantage of the momentum and methodological developments generated by the Varves Working Group in recent years, progress in very high-resolution (annually to seasonally resolved) quantitative climate reconstructions and reconstructions of environmental and vegetation change from varved lake sediments was shown. Robust quantitative paleoclimate signals can be extracted from biological proxies (chironomids, chrysophyte stomatocysts), while most of the biogeochemical and sedimentological

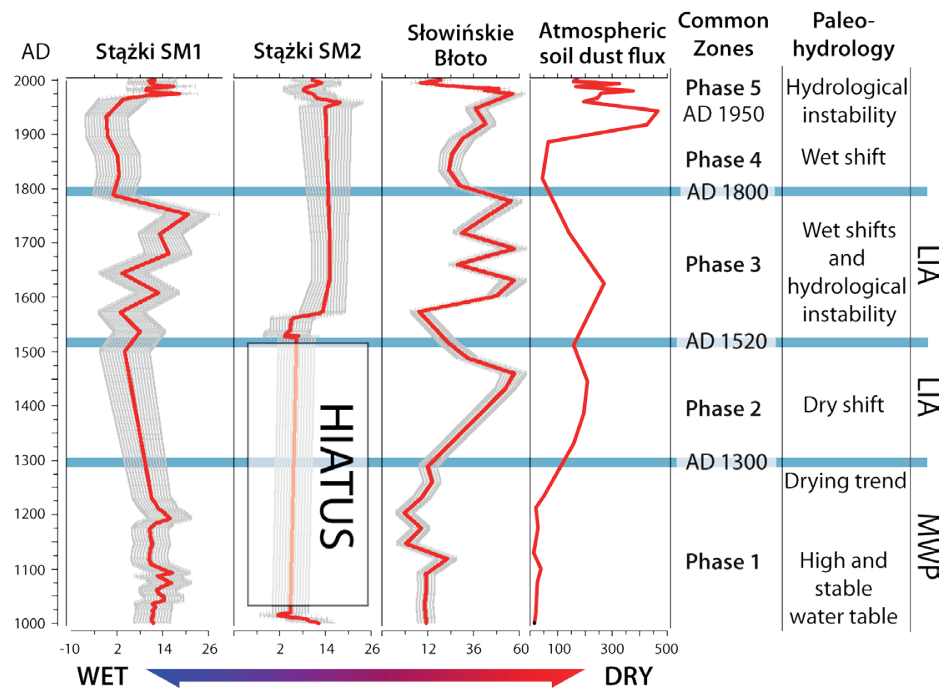

Figure 1: Hydroclimate variability of the last millennium reconstructed from northern Polish bogs using testate amoebae transfer functions (courtesy of Mariusz Lamentowicz).

proxies contain mixed signals and are more difficult to interpret and quantify. Separating climate variability from anthropogenic impacts still remains a challenge.

This part of Europe is very rich in peat bogs. Several presentations demonstrated the potential of testate amoebae transfer functions for quantitative reconstructions of bog humidity (Depth to Water Table DWT) and, thus hydroclimate (Fig. 1). The currently available records show systematically dry conditions and hydrological instability during the Little Ice Age (14-19 th centuries), which is in contrast to conditions in Western Europe during this period. It appears that there is more spatial heterogeneity in hydroclimatic conditions across Europe than previously thought.

The aims and plans of the recently established LandCover6k working group were presented during the meeting. The importance of land-atmosphere coupling is increasingly recognized, in particular the effect of land-use and land-cover change (LUCC) on regional temperatures. Central and Eastern Europe is a key site for the study of past land-atmosphere couplings, mainly because of the very large number of sites that have been studied for pollen and vegetation changes. These data, in combination with very rich and detailed information about past land-cover changes and hydrological modifications from historical cartography and other documentary sources, might make Central Europe a suitable test bed for calibrating and verifying pollen-based LUCC reconstructions and investigating land-cover feedbacks on the regional atmosphere in the past.

\section{ACKNOWLEDGEMENTS}

The organizers thank PAGES, CLIMPOL (PSPB086/2010), and the University of Gdansk for financial support. Meeting website: www.climate2k.ug.edu.pl

\section{AFFILIATIONS}

${ }^{1}$ Faculty of Oceanography and Geography, University of Gdańsk, Poland

2Oeschger Centre for Climate Change Research, University of Bern, Switzerland

\section{CONTACT}

Wojciech Tylmann: wojciech.tylmann@ug.edu.pl

\section{REFERENCES}

Lamentowicz et al. (2011) Stud Quat 28: 3-16

PAGES 2k Consortium (2013) Nat Geosci 6: 339-346

Tylmann et al. (2013) J Paleolimnol 50: 487-503 